\title{
Review
}

\section{Mysterious a6-containing nAChRs: function, pharmacology, and pathophysiology}

\author{
Ke-chun YANG ${ }^{1,2}$, Guo-zhang JIN ${ }^{2}$, Jie WU ${ }^{1, *}$ \\ ${ }^{1}$ Divisions of Neurology, Barrow Neurological Institute, St Joseph's Hospital and Medical Center, Phoenix, AZ 85013, USA; Department of Pharmacology, \\ Shanghai Institute of Materia Medica, Chinese Academy of Sciences, Shanghai 201203, China
}

\begin{abstract}
Neuronal nicotinic acetylcholine receptors (nAChRs) are the superfamily of ligand-gated ion channels and widely expressed throughout the central and peripheral nervous systems. nAChRs play crucial roles in modulating a wide range of higher cognitive functions by mediating presynaptic, postsynaptic, and extrasynaptic signaling. Thus far, nine alpha (a2-a10) and three beta $(\beta 2, \beta 3$, and $\beta 4$ ) subunits have been identified in the CNS, and these subunits assemble to form a diversity of functional nAChRs. Although a $4 \beta 2$ - and a7-nAChRs are the two major functional nAChR types in the CNS, a6*-nAChRs are abundantly expressed in the midbrain dopaminergic (DAergic) system, including mesocorticolimbic and nigrostriatal pathways, and particularly present in presynaptic nerve terminals. Recently, functional and pharmacological profiles of a $66^{*}$-nAChRs have been assessed with the use of a6 subunit blockers such as a-conotoxin MII and PIA, and also by using a6 subunit knockout mice. By modulating DA release in the nucleus accumbens (NAc) and modulating GABA release onto DAergic neurons in the ventral tegmental area (VTA), a6 $6^{*}$-nAChRs may play important roles in the mediation of nicotine reward and addiction. Furthermore, $a 6^{*}-n A C h R s$ in the nigrostriatal DAergic system may be promising targets for selective preventative treatment of Parkinson's disease (PD). Thus, a $6^{*}$-nAChRs may hold promise for future clinical treatment of human disorders, such as nicotine addiction and PD. In this review, we mainly focus on the recent advances in the understanding of a6*-nAChR function, pharmacology and pathophysiology.
\end{abstract}

Keywords: alpha 6-nicotinic acetylcholine receptor; dopaminergic neuron; a-conotoxin; nicotine reinforcement; Parkinson's disease Acta Pharmacologica Sinica (2009) 30: 740-751; doi: 10.1038/aps.2009.63

\section{Introduction}

Neuronal nicotinic acetylcholine receptors (nAChRs) belong to the ligand-gated ion channel superfamily, which include $\mathrm{GABA}_{\mathrm{A}}$, glycine, and 5-HT receptors $^{[1]}$. nAChRs are widely distributed throughout the central nervous system (CNS) and activation of various nAChRs may play important roles in regulation of higher cognitive functions ${ }^{[2]}$. nAChRs are pentameric complexes made up of combinations of a number of different $\mathrm{nAChR}$ subunits, which can be classified as alpha subunits, containing two cysteine residues at positions analogous to Cys192 and Cys193, and non-alpha subunits ('structural' subunits), which can be defined as beta subunits when they are expressed in the vertebrate nervous system ${ }^{[3,4]}$. To date, nine alpha subunits $(\alpha 2-\alpha 10)$ and three beta subunits $(\beta 2, \beta 3$, and $\beta 4)$ have been identified in the $\mathrm{CNS}^{[\varsigma]}$. A single

* Correspondence to Jie WU, MD, PhD.

E-mail Jie.Wu@chw.edu

Received 2009-03-01 Accepted 2009-04-10 subunit is about 600 amino acids long and has four separate transmembrane segments (TM1-TM4) with a large $\mathrm{N}$ - and a small C-termini facing the synaptic cleft ${ }^{[6,7]}$. Studies using affinity labeling and mutagenesis suggest that ligand-binding sites are located at the interfaces of the $\mathrm{N}$-terminal hydrophilic domain of $\alpha$ subunit and its adjacent $\alpha / \beta$ subunit ${ }^{[8]}$, and the wall of the ionic pore is formed by the second hydrophobic transmembrane segment (TM2) of each subunit ${ }^{[6,7]}$. The cation channel (mainly permeable to $\mathrm{Na}^{+}$and $\mathrm{Ca}^{2+}$ ) can be opened only when the receptor is activated by endogenous acetylcholine (ACh) or exogenous ligand (eg nicotine) binding to the binding site (Figure 1$)^{[7]}$. Furthermore, the $\beta$ subunits also largely contribute to the physiological and pharmacological properties (such as desensitization, inward rectification, and functional rundown) of the receptors ${ }^{[9,10]}$.

Physiological and pharmacological profiles of $\mathrm{nAChRs}$ range widely, depending on subunit co-assembly. nAChRs can be divided into two subfamilies, homomeric nAChRs (native $\alpha 7$ or heterologously expressed $\alpha 7-9$ subunits) and 

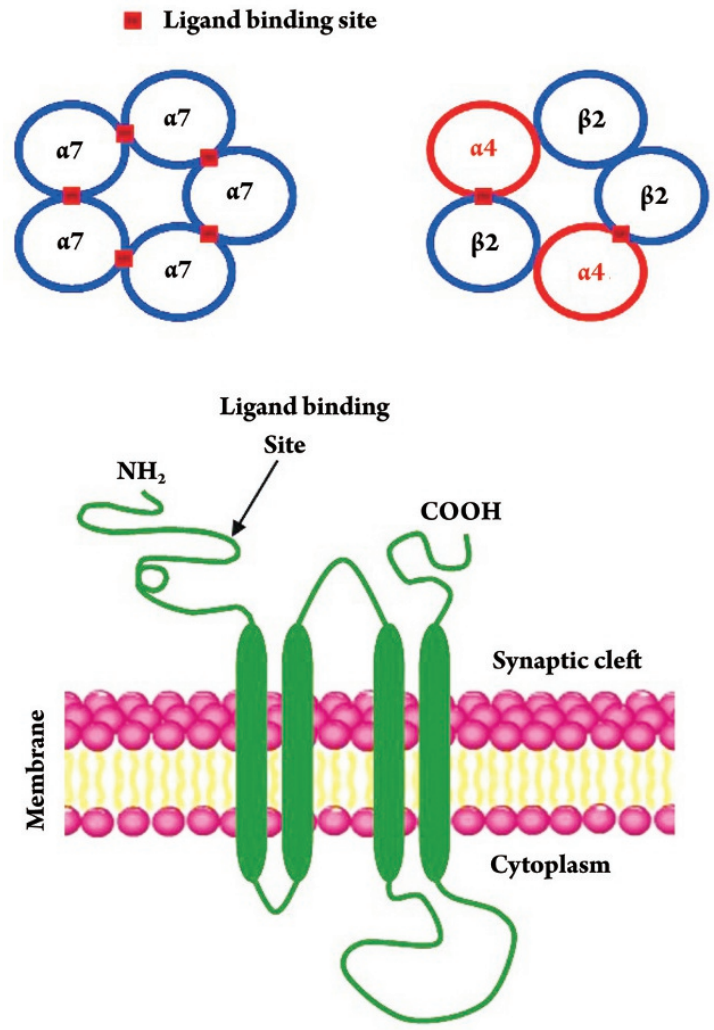

Figure 1. Structure of nAChRs. nAChRs are formed by five subunits, which can be either homomeric $(\alpha)$ or heteromeric $(\alpha / \beta)$. (A) Organization of subunits in neuronal homomeric $\alpha 7-n A C h R s$ and heteromeric $\alpha 4 \beta 2$-nAChRs. (B) One subunit of the nAChR contains (1) a large $\mathrm{N}$ - and a small C-terminal extracellular domains, (2) four transmembrane domains (M1-M4), and (3) a long cytoplasmic loop between M3 and M4.

heteromeric nAChRs ( $\alpha 2-6$ subunits combined with $\beta$ subunits $)^{[8,11]}$. Although there are many possible combinations of neuronal $\alpha$ and $\beta$ subunits, the majority of functional heteromeric $n A C h R s$ expressed throughout the brain are $\alpha 4 \beta 2$-containing nAChRs $\left(\alpha 4 \beta 2^{*}\right.$-nAChRs, *indicates the presence of possible additional subunits ${ }^{[12]}$. Though $\alpha 6^{*}$ nAChRs were characterized in the early $1990{ }^{\prime} \mathrm{s}^{[13,14]}$, it was not reported that $a 6$ subunit could form functional heteromeric nAChRs until $1997^{[15]}$. Immunoprecipitation experiments demonstrated that not only $\alpha 4 \beta 2$-nAChRs, but also heteromeric $\alpha 6^{*}$-nAChRs (ie, $\alpha 6 \beta 2$ - and $\alpha 4 \alpha 6 \beta 2$-nAChRs) are highly expressed in mesolimbic DAergic system ${ }^{[16]}$. More importantly, $a 6^{*}$-nAChRs expressed on DAergic neurons can be activated by endogenous $\mathrm{ACh}$ or exogenous nicotine and analogs, which suggest that the activation of $a 6^{*}$-nAChRs may play vital roles in central cholinergic circuits, including modulation of locomotor behaviour and drug addiction ${ }^{[17,18]}$. In addition, $\alpha 6^{*}$-nAChRs are particularly susceptible to nigrostriatal damage, which may lead to Parkinson's disease $(P D)^{[19,20]}$. Accumulating evidence suggests that $a 6^{*}$-nAChRs might represent as potential therapeutic targets for treatment of PD and addictive behaviors ${ }^{[18-21]}$.

Although $a 6^{*}$-nAChRs are abundant in the midbrain, they have been studied to a lesser extent than $\alpha 4 \beta 2$-nAChRs or $\alpha 7-n A C h R s^{[22]}$. In fact, we are only beginning to understand $a 6^{*}$-nAChR distribution, physiology and pharmacology, and the roles of these receptors in various diseases. In this review, we focus on recent advances in the understanding of $a 6^{*}$ nAChRs.

\section{Anatomical distribution of $\alpha 6^{*}$-nAChRs}

Overwhelming experimental evidence demonstrates that neuronal nAChRs are present in a variety of regions of the brain, but the situation is much different for $a 6^{*}$-nAChRs, which are not abundantly expressed in the whole brain, but only detected in a restricted number of brain areas ${ }^{[23-25]}$. For example, in order to detect $a 6$ subunit mRNA distribution in the CNS, Le Novere and colleagues explored the telencephalon, diencephalon, mesencephalon, and rhombencephalon of adult rat brain using in situ hybridization ${ }^{[23]}$ and found that the amount of $a 6$ subunit mRNA is particularly high in several catecholaminergic nuclei, including locus coeruleus, ventral tegmental area (VTA) and substantia nigra (SN). In reticular thalamic nucleus, supramammillary nucleus, interpeduncular nucleus, medial and lateral habenula, and mesencephalic V nucleus, $\alpha 6$ subunit mRNA can be detected, but at lower levels, while no detectable $\alpha 6$ subunit mRNA labeling is observed in the anterior pretectal area ${ }^{[23]}$. Based on these data, authors concluded that $a 6^{*}$-nAChRs are the primary $\alpha$ subunit expressed in DAergic cell groups within the midbrain ${ }^{[23]}$. After this initial report, subsequent studies confirmed that $a 6^{*}$ nAChRs are highly expressed in the SN and VTA, and particularly expressed on most midbrain DAergic neurons rather than on non-DAergic neurons, either by applying single-cell reverse transcription polymerase chain reaction (RT-PCR) and patch-clamp recording in slices from rats, wild-type mice and $a 6$ subunit null mutant mice ${ }^{[25]}$ or using double-labeling in situ hybridization in rats ${ }^{[24]}$. Additional in situ hybridization experiments using specific probes and stringent hybridization conditions demonstrated that $a 6$ subunit mRNA is also abundantly expressed in neuroretina ${ }^{[26]}$. Other studies using $\left[{ }^{125} \mathrm{I}\right] \alpha$-CTX MII binding indicate that high levels of $\alpha 6^{*}$ nAChRs are expressed in the visual system, including retina, optic tract, and its terminal fields, including geniculate nucleus, zonal and superficial gray layer, and olivary pretectal nucleus ${ }^{[27]}$. Although nAChRs are widely distributed in the 
peripheral nervous system (PNS) ${ }^{[28]}$, no a6 subunit mRNA has been detected in the PNS (ciliary, superior cervical, sympathetic, dorsal root, nodose and petrous ganglia), except in trigeminal nucleus and trigeminal ganglion ${ }^{[26,29]}$. Thus, we can draw the conclusion that the natural expression of $\alpha 6^{*}$ nAChRs appears to be largely excluded from the PNS and mainly restricted to the CNS, and particularly enriched in midbrain catecholaminergic nuclei.

Neuronal $\mathrm{nAChRs}$ are located postsynaptically on the cellbody, where they mediate direct postsynaptic effects and/or regulate firing patterns of DAergic neurons ${ }^{[30]}$, or presynaptically/preterminally on nerve terminals ${ }^{[16,22,31]}$, where they modulate neurotransmitter release $\mathrm{s}^{[5,32-35]}$. Immunoprecipitation experiments have found that $\alpha 6^{*}$-nAChRs account for $30 \%$ of ${ }^{3} \mathrm{H}$-Epibatidine (Epi) binding sites in striatum but only $5 \%$ in SN/VTA ${ }^{[16]}$. Furthermore, quantitative immunoprecipitation experiments have shown that most of $a 6^{*}$ nAChRs (87\%) disappeared in 6-hydroxydopamine lesioned (6-OH DA) striatum ${ }^{[36]}$, further demonstrating the regulatory effects of presynaptic $a 6^{*}$-nAChRs on DA release ${ }^{[37,38]}$. These results indicate that $a 6^{*}$-nAChRs appear to be preferentially addressed to DAergic nerve terminal compartments, since the majority of DAergic neurons in the SN project to the striatum ${ }^{[16,36]}$. Our recent results using RT-PCR and patch clamp recordings in freshly dissociated VTA DAergic neurons ${ }^{[22]}$ are in good agreement with these observations. Tissue RT-PCR data showed that $\mathrm{nAChR} \alpha 6$ subunit mRNA levels are $>20$-fold higher in the VTA than that of other subunits ${ }^{[22]}$, suggesting that $a 6^{*}$-nAChRs are mainly concentrated in midbrain catecholaminergic nuclei. However, 100 nmol/L $\alpha$-conotoxin MII ( $\alpha$-CTX MII), an $\alpha 6 / \alpha 3-n A C h R$ subtype-selective antagonist, had no significant effect on $\mathrm{ACh}$ $(1 \mathrm{mmol} / \mathrm{L})$ induced postsynaptic inward currents on all three subtypes of nAChRs on VTA DAergic neurons ${ }^{[22]}$, suggesting that there are likely no functional $\alpha 6^{*}$-nAChRs expressed on VTA DAergic neuronal somata under physiological conditions. Importantly, $\alpha$-CTX MII $(100 \mathrm{nmol} / \mathrm{L})$ inhibited GABAergic spontaneous inhibitory postsynaptic currents in DAergic neurons containing GABAergic presynaptic boutons that were mechanically dissociated from the $\mathrm{VTA}^{[22]}$, implicating that most of the functional $a 6^{*}$-nAChRs are located on presynaptic structures rather than on somata of DAergic neurons in the VTA, or that functional $\alpha 6^{*}$-nAChRs are expressed on somatodendrites of VTA DAergic neurons under the natural conditions, but the expression level is too low to be detected using patch-clamp recording. One recent paper supports this hypothesis, which shows that after genetic enhancement of $\alpha 6^{*}$-nAChR expression, the function of $a 6^{*}$-nAChRs can be clearly tested using whole-cell recording technique ${ }^{[39]}$.
Therefore, nAChR a6 subunit mRNA is specifically expressed in DAergic neurons in the VTA and SN, and functional $a 6^{*}$-nAChRs are preferentially located on presynaptic nerve terminals.

\section{Subunit composition of functional $a 6^{*}-n A C h R s$}

Studies using single-cell RT-PCR and patch-clamp recordings demonstrated that eight $\mathrm{nAChR}$ subunits ( $\alpha 3-7$ and $\beta 2-4)$ are expressed on DAergic neurons in the VTA and $\mathrm{SN}^{[25]}$, and the combination of some these subunits with a6 subunit can form several subtypes of nAChRs. One of them possesses a putative $\alpha 4 \alpha 6 \alpha 5(\beta 2)_{2}$ composition since the whole cell currents mediated by this kind of $\mathrm{nAChR}$ can be inhibited by both $\mathrm{DH} \beta \mathrm{E}$ and $\alpha$-CTX MII ${ }^{[25]}$. Immunoprecipitation results from the same group found that $\alpha 4, a 6$, and $\beta 2$ are the most abundant $\mathrm{nAChR}$ subunits in the striatum $^{[16]}$. Thus, it is reasonable to believe that the composition of naturally expressed functional $a 6^{*}$-nAChRs is very complex.

As early as 1982, researchers began to study nAChRs heterologously expressed in Xenopus oocytes and demonstrated that functional nAChRs could be inserted in the oocyte membrane and that activity of functional nAChRs could be measured using voltage clamp recording ${ }^{[40,41]}$. Since then, Xenopus oocytes have become one of the most practical and widely used systems to express and study the physiological and pharmacological properties of $\mathrm{nAChRs} s^{[9,15,42-46]}$. It is quite difficult, however, to express functional $a 6^{*}$-nAChRs in vitro. Fifteen years later, Gerzanich and co-workers found that $\alpha 6$ may form detectable functional $\alpha 6^{*}$-nAChRs when chicken $\alpha 6$ subunit is expressed together with human $\beta 4$ subunit ${ }^{[15]}$. This was the first in vitro synthesized functional $a 6^{*}$-nAChRs, proving that the $a 6$ is not the so called "orphan" subunit. Kuryatov et al have tested even more complex mixtures of $\alpha 6$ with several other $\mathrm{nAChR}$ subunits and found that the coexpression of $\alpha 6, \beta 4$, and $\beta 3$ subunit can produce the most efficient $\alpha 6^{*}$-nAChRs with the largest and most consistent responses ${ }^{[44]}$. Meanwhile, a complex variety of functional $\alpha 6^{*}$-nAChRs, including $\alpha 6 \alpha 3 \beta 2$-nAChRs, $\alpha 6 \alpha 4 \beta 2$-nAChRs, $\alpha 6 \beta 2 \beta 4-n A C h R s, \alpha 6 \beta 2 \alpha 5$-nAChRs, $\alpha 6 \beta 4 \beta 3 \alpha 5-n A C h R s$, $\alpha 6 \beta 4-n A C h R s$, and chimeric $\alpha 6 / \alpha 3 \beta 2 \beta 3-n A C h R s$ and $\alpha 6 /$ $\alpha 4 \beta 2 \beta 3-n A C h R s$ were synthesized ${ }^{[43-46]}$. But cotransfections of $\alpha 6$ and $\alpha 3$ without a $\beta$ subunit can not yield functional receptors ${ }^{[26]}$. Interestingly, $a 6$ subunit cotransfected with $\beta 2$ and(or) $\beta 3$ subunit either can form nAChR without gated ion channels thus can not further yield functional $\alpha 6 \beta 2$ - or $\alpha 6 \beta 2 \beta 3$-nAChRs in Xenopus oocytes ${ }^{[15,44]}$, or can form $\alpha 6 \beta 2$-nAChRs with very poor function in transfected 
cell line ${ }^{[26]}$, even though these subunits can form different ligand binding sites with high affinity for Epi ${ }^{[44]}$. Thus far, in vitro synthesized functional $a 6^{*}$-nAChRs are very valuable preparations for development and testing specific $a 6^{*}$-nAChR antagonists ${ }^{[43,45,47]}$. However, in vitro synthesized functional receptors can only shed light on the possibilities of the in vivo receptors because complex subunit combinations of naturally expressed $a 6^{*}$-nAChRs that exist in vivo are not easily recreated in in vitro systems.

In the past decade, several research groups have tried to further define the possible compositions of $\alpha 6^{*}$-nAChRs naturally expressed in neurons. Le Novere and co-workers reported the extensive colocalization of $\alpha 6$ and $\beta 3$ subunits and were the first to propose the existence of heteromeric $\alpha 6^{*}$-nAChRs containing both $\alpha 6$ and $\beta 3$ subunits in catecholaminergic nuclei ${ }^{[23]}$. Further definition of the exact subunit compositions of naturally-expressed functional $\alpha 6^{*}$ nAChRs remains challenging. Studies on rats and both wild type and several types of nAChR subunit-null mice (eg a $4-/-$, $\alpha 6-/-, \alpha 4-/-\alpha 6-/-$, and $\beta 2-/-)$, using combined single-cell RT-PCR, patch-clamp recording, in vivo microdialysis, and immunoprecipitation techniques, have demonstrated that a putative $\alpha 4 a 6 \alpha 5(\beta 2)_{2}$ composition is present on the somata of DAergic neurons in the SNc and VTA ${ }^{[25]}$. Meanwhile, two types of $\alpha 6^{*}$-nAChRs ( $\alpha 6 \beta 22^{*}$-nAChRs and $\alpha 4 \alpha 6 \beta 2^{*}$ $\mathrm{nAChRs)}$ are expressed in DAergic neuronal terminal fields located in the striatum ${ }^{[16]}$. Salminen and colleagues further demonstrated that the presence of presynaptic $\alpha$-CTX MIIsensitive nAChRs ( $\alpha 6^{*}$-nAChRs) on DAergic nerve terminals in striatal synaptosomes plays important roles in mediating $D A$ release. The more interesting finding is that in $\beta 2$-null mutant mice $(\beta 2-/-)$, the $\alpha$-CTX MII-sensitive DA release completely disappeared, while only $50 \%$ decrease of $\alpha$-CTX MII-sensitive DA release resulted from $\beta 2+/$ - mutation, which indicates that the $\beta 2$ subunit is an indispensable component for the $\alpha$-CTX MII-sensitive nAChR-mediated DA release ${ }^{[37]}$. Additional studies found that deletion of $\beta 3$ or $\alpha 4$ decreased the $\alpha$-CTX MII-sensitive component of DA release by $76 \%$ or $55 \%$, respectively. Neither $\beta 4$ nor $\alpha 7$ gene deletion significantly altered $\alpha$-CTX MII-sensitive DA release ${ }^{[37]}$. These results suggest that $\beta 3$ and $\alpha 4$ rather than $\alpha 7$ and $\beta 4$ subunits play important roles in forming naturally expressed functional $\alpha 6^{*}$-nAChRs ( $\alpha 6 \beta 3 \beta 2$ and $\alpha 4 \alpha 6 \beta 3 \beta 2$ ) on DAergic presynaptic terminals ${ }^{[37]}$. The compositions of $a 6^{*}$-nAChRs in chick retina (from 1-day old chicks) are quite different from that in catecholaminergic nuclei. For example, one study showed that only a minor subpopulation of $\alpha 6^{*}$ nAChRs (7.5\%) contain the $\beta 2$ subunit, but almost all of the $\alpha 6$ receptors contain the $\beta 4$ subunit in chick retina ${ }^{[48]}$. The presence of a mixture of different populations of $a 6^{*}$-nAChRs (surely $\alpha 6 \beta 4$; probably $\alpha 6 \beta 4 \beta 3, \alpha 3 \alpha 6 \beta 4$, and/or $\alpha 3 \alpha 6 \beta 3 \beta 4$ ) is found in chick retina ${ }^{[48]}$. However, Moretti et al reported that $a 6^{*}$-nAChRs expressed in rat retina (postnatal 21d) mainly contain the $\alpha 6 \beta 3 \beta 2, \alpha 6 \alpha 4 \beta 3 \beta 2$, and $\alpha 6 \alpha 3 \alpha 2 \beta 3 \beta 2$ subtypes ${ }^{[49]}$.

We have described the known diversity of naturally expressed functional $a 6^{*}$-nAChR subunit compositions, which vary in different brain regions or even within the same tissue from different species or different developmental periods within the same specie. This indicates the complex roles of $a 6^{*}$-nAChRs in physiological and perhaps in pathological states. As a result, the improving knowledge of subtype composition of $a 6^{*}$-nAChRs will be of considerable importance for development of selective and specific $a 6^{*}$-nAChR agonists and antagonists.

\section{Analogs of $a$-conotoxins are subunit-selective antagonists of $\alpha 6^{*}$-nAChRs}

It is still a challenge to develop selective agonists and antagonists for $a 6^{*}$-nAChRs due to the complex subunit combinations of naturally expressed $\alpha 6^{*}$-nAChRs and poor function in heterologous expression systems. Until now, the only reported selective agonist for $a 6^{*}$-nAChRs is TC 2429, which is a full agonist with 3 -fold more selectivity at $\alpha 6 \beta 2^{*}$-nAChRs compared to nicotine ${ }^{[39]}$. But $\alpha 6^{*}$-nAChRs can be selectively inhibited by several analogs of $\alpha$-conotoxins ${ }^{[25,39,43,45]}$. Conotoxins can be divided into at least four superfamilies (A, M, O, and S) based on a conserved signal sequence and a characteristic disulfide framework that is distinct from the other superfamiles ${ }^{[50]}$. $\alpha$-conotoxins, which are competitive $\mathrm{nAChR}$ antagonists, belong to the largest family of peptides in the A superfamily ${ }^{[50]}$. Several $\alpha$-conotoxins are pharmacologically useful for distinguishing nAChR subtypes. For example, $\alpha 7^{*}$-nAChRs can be inhibited by selective antagonist $\alpha$-CTX $\operatorname{ImI}{ }^{[51]}, \alpha 3 \beta 4^{*}-n A C h R s$ by antagonist $\alpha-\mathrm{CTX} \mathrm{AuIB}^{[52]}$, and $\alpha 6^{*}$-nAChRs by selective antagonist $\alpha$-CTX MII and $\alpha$-CTX PIA $^{[39,45]}$.

Electrophysiological experiments using Xenopus oocytes expressing mammalian neuronal $\mathrm{nAChRs}$ have demonstrated that $\alpha$-CTX MII is a novel, potent, selective, and competitive antagonist for $\alpha 3 \beta 2$-nAChRs, which can reversibly block acetylcholine (ACh)-induced inward currents at very low concentration $\left(\mathrm{IC}_{50} \text { is } 0.5 \mathrm{nmol} / \mathrm{L}\right)^{[53]}$. $\alpha$-CTX MII is the first $\alpha$-conotoxin known to target neuronal $\alpha 3 \beta 2$-nAChRs ${ }^{[53]}$. However, $\alpha$-CTX MII is now widely used as a selective $\alpha 6^{*}$ nAChR antagonist, especially in midbrain DAergic system because: (1) there is high structural similarity between the $\alpha 3$ and $\alpha 6$ subunits, $61 \%^{[17,23]}$ to $80 \%^{[47]}$ residue identity in their 
extracellular ligand-binding domains, and critical residues responsible for interaction with $\alpha$-CTX MII ${ }^{[54]}$ are conserved; (2) $\alpha 6^{*}$ - but not $\alpha 3^{*}$-nAChRs are highly expressed in midbrain DAergic system: studies demonstrated that $a 6$ labeling is almost 20 -fold more intense than $\alpha 3$ labeling in DAergic neurons ${ }^{[23]}$, while $\alpha 3$ subunit only accounts for $2 \%$ of ${ }^{3} \mathrm{H}$-Epi binding sites at the DAergic terminal levels ${ }^{[16]}$. Moreover, electrophysiological recordings and in vivo microdialysis experiments showed that the inhibitory effect of $\alpha$-CTX MII on ACh-induced inward currents and nicotine-induced DA release disappear in $\alpha 6^{-/-}$mice ${ }^{[16]}$; and (3) $\alpha$-CTX MII is a selective antagonist for naturally expressed $a 6^{*}$-nAChRs: high-affinity $\left[{ }^{125} \mathrm{I}\right] \alpha$-CTX MII binding sites are well preserved in $\alpha 3-\mathrm{nAChR}$ subunit knockout mice ${ }^{[55]}$, but can not be detected in a6-nAChR subunit knockout mice ${ }^{[16,27]}$. Therefore, $a$-CTX MII, even at a high concentration, eg 100 $\mathrm{nmol} / \mathrm{L}$, can be used to study the function of $\alpha 6^{*}$-nAChRs in midbrain DAergic neurons ${ }^{[39]}$. Recently, scientists discovered a novel $\alpha$-conotoxin, $\alpha$-CTX PIA, which has higher affinity and selectivity for $\alpha 6^{*}$ than $\alpha 3^{*}$-nAChRs, exhibiting $\sim 75$-fold lower $\mathrm{IC}_{50}$ for $\alpha 6 / \alpha 3 \beta 2 \beta 3$-nAChRs than for $\alpha 3 \beta 2$ $n A C h R s^{[45]}$. $\alpha$-CTX PIA is able to specifically distinguish $\alpha 6^{*}$-nAChRs from $\alpha 3^{*}$-nAChRs due to its lower affinity for $\alpha 3^{*}$-nAChRs. Another $\alpha$-conotoxin, $\alpha$-CTX BuIA, displays strong antagonistic effect on chimeric $\alpha 6 / \alpha 3 \beta 2 \beta 3$ and $\alpha 3 \beta 2$ $\mathrm{nAChRs}{ }^{[56,57]}$ with an $\mathrm{IC}_{50}$ of $0.26 \mathrm{nmol} / \mathrm{L}$ and $5.7 \mathrm{nmol} / \mathrm{L}$ for $\alpha 6 / \alpha 3 \beta 2 \beta 3$-nAChRs and $\alpha 3 \beta 2$-nAChRs, respectively ${ }^{[57]}$. All of these $\alpha$-conotoxins have the ability to selectively discriminate $\alpha 6^{*}$-nAChRs from a variety of nAChR subtypes. In addition, the chemical structure of $\alpha$-conotoxins (only 12-19 amino acids) is relatively simple (with highly conserved nature of the cysteine residues and conserved proteolytic processing sites), which has allowed them to be isolated and their structure sequences identified and synthesized ${ }^{[45]}$. Scientists are trying to modify the natural structure and synthesize new analogs of $\alpha$-conotoxins. For example, substitution of Leu15 with Ala, Glu11 with Ala, and Ala for His9 shifts the selectivity of $\alpha$-CTX MII toward $\alpha 6^{*}$-nAChRs, with approximately 37-, 54-, and 75-fold higher preference for $\alpha 6^{*}$ - than for $\alpha 3^{*}$ nAChRs $s^{[38]}$, respectively. In addition, Azam et al have successfully designed and synthesized $\alpha$-CTX MII[S4A, E11A, L15A], which displays more selectivity for $a 6^{*}$-nAChRs with an $\mathrm{IC}_{50}$ of $1.2 \mathrm{nmol} / \mathrm{L}$, and much lower affinity for $\alpha 3 \beta 2$ nAChRs with an $\mathrm{IC}_{50}$ of $1400 \mathrm{nmol} / \mathrm{L}^{[43]}$.

In conclusion, several isolated natural and chemically-synthesized analogs of $\alpha$-conotoxin have been used as powerful $\alpha 6$ subtype-selective antagonists to investigate physiological and pharmacological properties of the in vitro synthesized- and the in vivo naturally-expressed functional $\alpha 6^{*}$-nAChRs. Such pharmacological tools will, undoubtedly, be of considerable benefit to further understanding of $a 6^{*}$-nAChR function and pharmacology. A more detailed review by Azam et al of the applications of $\alpha$-conotoxin analogs for $\mathrm{nAChR}$ studies can be found in this issue.

\section{The potential role of presynaptic $a 6^{*}$-nAChRs in nicotine reward and dependence}

The mesocorticolimbic system including VTA DAergic neurons and their projection areas is postulated to play a crucial role in regulation of cognitive functions, rewardbased learning, and addiction ${ }^{[58-60]}$. Numerous nAChRs are expressed in the VTA and some of them are located extra-synaptically on somatodendritic regions and on presynaptic terminals. Somatodendritic nAChRs modulate neuronal excitation via membrane depolarization and can initiate short- and long-term changes by interfacing with $\mathrm{Ca}^{2+}$ signaling pathways or the firing pattern of DAergic neurons that determines the release of DA in the terminal regions ${ }^{[61,62]}$. The modulation of neurotransmitter release by pre-synaptic nAChRs is one of the most well-investigated effects of nicotine in the $\mathrm{CNS}^{[33]}$. Activation of pre-synaptic $n A C h R s$ increases the release of many different neurotrans-

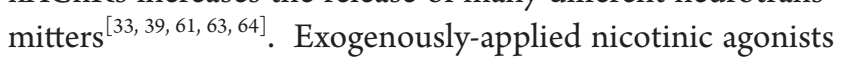
can enhance, while nicotinic antagonists often can diminish the release of $\mathrm{ACh}, \mathrm{DA}$, norepinephrine, serotonin, as well as glutamate and $\mathrm{GABA}^{[65]}$. The activation of pre-synaptic nAChRs initiates directly or indirectly intracellular $\mathrm{Ca}^{2+}$ signals that potentiate neurotransmitter release through the following mechanisms: (1) a small, direct $\mathrm{Ca}^{2+}$ influx via nAChR activity ${ }^{[6-68]}$ that (2) may trigger $\mathrm{Ca}^{2+}$-induced $\mathrm{Ca}^{2+}$ release from intracellular $\mathrm{Ca}^{2+}$ stores ${ }^{[69]}$, and (3) the activation of $\mathrm{nAChRs}$ further causes membrane depolarization that activates voltage-gated $\mathrm{Ca}^{2+}$ channels in pre-synaptic terminals ${ }^{[70]}$. The overall effect is that pre-synaptic nAChR activity elevates $\mathrm{Ca}^{2+}$ levels in presynaptic terminals, in turn leading to an increase in neurotransmitter release.

The activation of nAChRs on VTA DAergic neurons by exogenously-applied nicotine results in increased DA release in the nucleus accumbens (NAc), which probably plays a key role in nicotine addiction ${ }^{[71,72]}$. Studies indicate that different subtypes of pre-synaptic nAChRs participate in the modulation of neurotransmitter release. It is supposed that by acting on presynaptic $\alpha 7$-nAChRs (desensitized less than non $\alpha 7$-nAChRs) located on glutamatergic terminals, nicotine at concentrations experienced by smokers can produce long-term enhancement of glutamatergic transmission in the $\mathrm{VTA}^{[73]}$, whereas activation of presynaptic non- $\alpha 7$ recep- 
tors (possibly $\alpha 4 \beta 2$-nAChRs) only can transiently enhance GABAergic transmission. These non- $\alpha 7 \mathrm{nAChRs}$ become significantly and quickly desensitized during long-term exposure to low concentrations of nicotine ${ }^{[74]}$. As a result, GABAergic terminals, rather than glutamatergic terminals, become insensitive to tonically released $\mathrm{ACh}$ from cholinergic afferents from the pedunculopontine tegmental nucleus (PPTg) and laterodorsal tegmental nucleus (LDTg) ${ }^{[75,76]}$, which will in turn lead to long-term activation of glutamatergic input accompanied with depression of GABAergic input to VTA DAergic neurons that is experienced by tobacco smokers. Collectively, the differential desensitization properties of these two nicotinic receptor subtypes probably explain why low concentrations of nicotine tends to drive the activity of VTA DAergic neurons toward long-term excitation that underlie the course of nicotine addiction process ${ }^{[77]}$. Thus, in vivo experiments observed that a single exposure to nicotine increases DA release in NAc from VTA for more than one hour ${ }^{[78,79]}$.

Our current studies demonstrate that there are functional $\alpha$-CTX MII and PIA sensitive nAChRs ( $\alpha 6^{*}$-nAChRs) located on GABAergic pre-synaptic boutons synapsing onto DAergic cell bodies in the VTA. Activation of these $a 6^{*}$ $\mathrm{nAChRs}$ by nicotinic agonists results in increased inhibitory postsynaptic currents (IPSCs) measured at the DAergic cell body using patch-clamp recordings. A 4-minute pretreatment with smoking-relevant concentrations of nicotine desensitizes rather than activates $a 6^{*}$-nAChRs and abolishes ACh-induced increases in spontaneuos IPSCs(sIPSCs) [80]. The results demonstrate that functional $a 6^{*}-n A C h R s$ are expressed on presynaptic GABAergic boutons in the VTA and likely play a critical role in mediating cholinergic modulation of GABA release. Their desensitization during chronic nicotine exposure may contribute to a disinhibition of VTA DAergic neuronal activity and enhanced DA release. Our findings suggest that $a 6^{*}$-nAChRs play important roles in nicotine-induced reinforcement through the modulation of GABAergic control on VTA DAergic neurons ${ }^{[80]}$. The observations are in good agreement with previous reports. An in vivo study of nicotine-induced increase in locomotor activity in a habituated environment found that 1 week administration of $a 6$ antisense oligonucleotides (directed against the $a 6$ subunit) by osmotic mini-pump suppresses $70 \%$ of the nicotine effect, which strongly suggests that enhanced locomotor activity elicited by nicotine is mediated at least in part via $a 6^{*}-n A C h R s^{[17]}$. Studies using striatal synaptosomes demonstrated a preponderant role of $\alpha 4 \alpha 6 \beta 22^{*}$-nAChRs in mediating the $\alpha$-CTX MII-sensitive part of nicotine-elicited DA release ${ }^{[16]}$, but the inhibitory effect of $\alpha$-CTX MII on nicotine-induced DA release in $a 6$ subunit knockout mice was no longer observed ${ }^{[16]} \cdot a 6^{*}$-nAChRs in the NAc also play a dominant role in DA release in an action potential frequency-dependent manner ${ }^{[81]}$, which is the first direct evidence of the dominant role of $\alpha 6^{*}$-nAChRs in dynamic filtering (frequency-sensitive regulation of DA neuronal activity and terminal DA release) of action potential-dependent DA release in the NAc. In addition, using patch clamp recordings in brain slice preparations from gain-of-function $a 6^{*}$-nAChR mice, Drenan et al demonstrated that in $\alpha 6$ transgenic mice, the $a 6^{*}$-nAChRs expressed on VTA DAergic neurons are $\sim 10$-fold more sensitive to nicotine than in locus coeruleus ${ }^{[39]}$, which suggests that functional $\alpha 6^{*}$-nAChRs can be detected on somatodendritic region of DAergic neurons after fuctional enhancement of $\alpha 6^{*}$-nAChR expression. These results suggest that the up-regulation of functional $\alpha 6^{*}$-nAChRs in the mesocorticolimbic system, such as the VTA and NAc, produces a hyperdopaminergic state that may play a critical role in nicotine dependence ${ }^{[82]}$. Meanwhile, nicotine self-administration investigated by Pons et al, using $\alpha 6$ and $\alpha 4$ knockout mice, highlighted the crucial roles of both $a 6^{*}$ - and $\alpha 4^{*}$ $\mathrm{nAChRs}$ in nicotine reinforcement ${ }^{[83]}$. It has been suggested that $\alpha 6^{*}$ - and $\alpha 4^{*}$-nAChRs can modulate action potential evoked DA-release from either a low action potential threshold or a higher action potential threshold DAergic fiber, respectively ${ }^{[84]}$. Thus, nAChRs may exert their roles through 'filtering' action, which will lead to an increase in contrast in DA signals by switching the firing pattern of DAergic neurons from tonic activity to high frequency, reward-related burst activity, thus facilitating the reinforcement properties of nicotine ${ }^{[85,86]}$.

Taken together, these studies suggest that nicotine at concentrations present in the plasma of tobacco smokers preferentially desensitizes both presynaptic $\alpha 6^{*}$ and $\alpha 4 \beta 2$ nAChRs on GABAergic neurons, whereas, nicotine has minimal desensitization effects on presynaptic $\alpha 7$-nAChRs located on glutamatergic terminals. Thus, endogenously released ACh can facilitate midbrain glutamate, but not GABA release, which leads to an increase in glutamate mediated excitatory inputs onto DAergic neurons in the VTA. As a result, nicotine induces both disinhibition and direct excitation of DAergic neurons, leading to an increased DA release in NAc (Figure 2).

\section{The potential role of presynaptic a $6^{*}-n A C h R s$ in Parkinson's disease}

Parkinson's disease (PD) was first described as Shaking Palsy in 1817 by the British physician James Parkinson. PD is one of the most common progressive neurodegenerative disorders in the United States, affecting about one million people, 

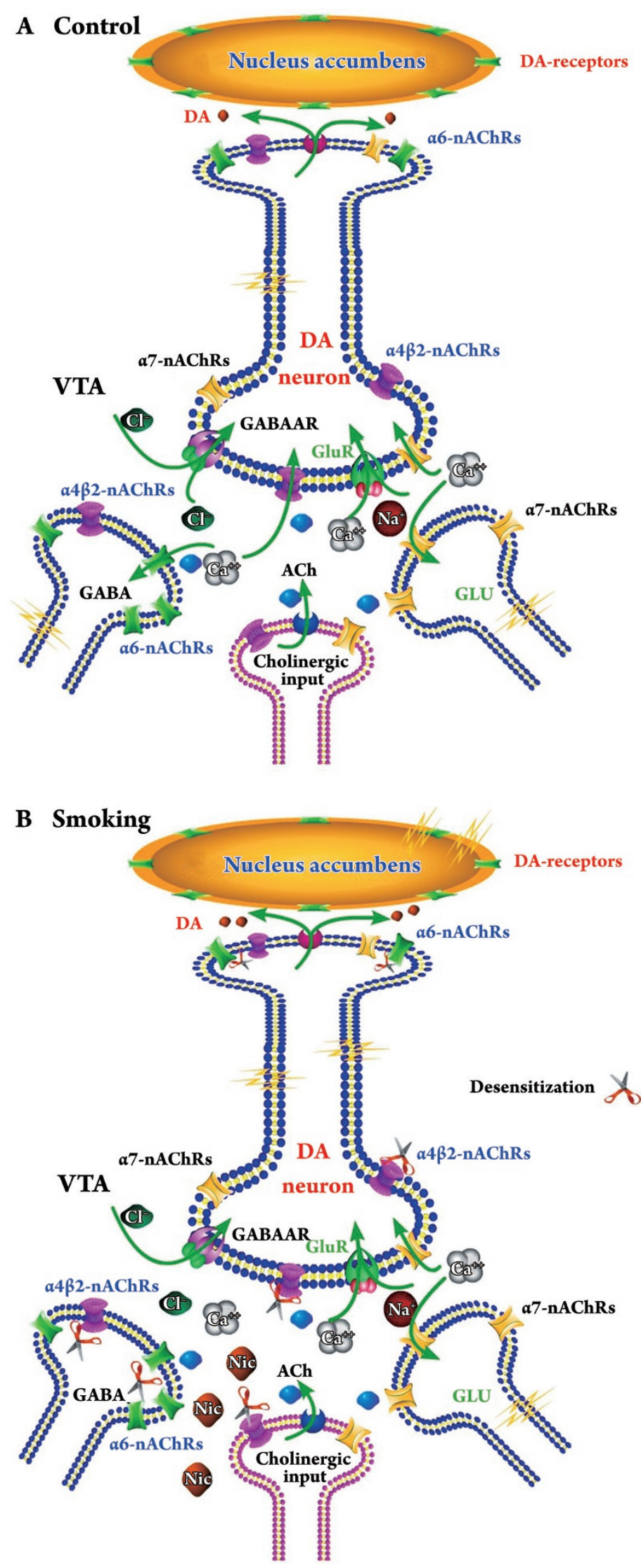

Figure 2. Simplified schematic diagram of the roles of $\mathrm{nAChRs}$ in the nicotine addiction process. In the VTA, $\alpha 6^{*}$ - and $\alpha 4 \beta 2$ $n A C h R s$ are located on GABAergic terminals and provide inhibitory inputs onto DAergic neuons, while $\alpha 7$-nAChRs are located on glutamatergic terminals and activation of these receptors enhances glutamate release and increases excitability of DAergic neurons. Endogenous ACh released from cholinergic terminals projected from PPTg and LDTg can modulate the excitability of both GABAergic and glutamatergic terminals. A: Under control conditions, endogenous ACh can activate $a 6^{*}$ and $\alpha 4 \beta 2$-nAChRs on GABAergic terminals and $\alpha 7-n A C h R s$ on glutamatergic terminals. Thus postsynaptic DAergic neurons will receive balanced inhibitory and excitatory inputs. B: In smoking conditions, $\alpha 6^{*}$ - and $\alpha 4 \beta 2$-nAChRs, rather than $\alpha 7$ $n A C h R s$, are desensitized rapidly after chronic exposure to low concentrations of nicotine, thus inhibiting GABAergic inhibitory inputs (disinhibition). But endogenous ACh can still significantly enhance glutamatergic inputs onto the DAergic neurons. As a result, the increased excitation of DAergic neurons will result in a net increase in DAergic neuron firing and more DA release in NAc. 
with more than 50000 new diagnosed cases each year ${ }^{[87]}$. The pathogenesis of PD typically is slow-paced but relentlessly progressive loss of DAergic neurons in the nigrostriatal DAergic system in the ventral midbrain ${ }^{[88]}$. Our understanding of the etiology of PD is still limited. Therefore, interventions to slow, halt or reverse the progression of the disease are crucial. Importantly, epidemiological studies indicate that cigarette smoking offers some protection against developing PD, as smokers with the longest duration of smoking and the highest daily consumption of cigarettes have the lowest PD risk ${ }^{[89]}$, which indicates that the protective effects of nicotine are doseand time-dependent, and the protective effects wane after smoking quit. In addition, results of both prospective and retrospective studies demonstrate that the decreased incidence of PD in smokers does not appear to be due to the increased smoking-related mortality ${ }^{[90-93]}$.

Accumulating lines of evidence indicate that smokers may have a lower incidence of PD through the following possible mechanisms: (1) nicotine directly activates $n A C h R s$ expressed on nigrostriatal DAergic neurons, stimulating DAergic neurons to release more $\mathrm{DA}^{[94,95]}$, which could partly overcome the nigrostriatal DAergic dysfunction in the disorder; (2) in vitro and in vivo studies suggest that nicotine exposure is neuroprotective against glutamate excitotoxicity, ischemic damage, and DAergic neurotoxic compounds such as 1-methyl-4-phenyl-1,2,3,6-tetrahydropyridine (MPTP), 6-hydroxydopamine, paraquat, and methamphetamine ${ }^{[90]}$, thus producing a neuroprotective effects ${ }^{[96,97]} ;(3)$ nicotine may exert its neuroprotective effects on DAergic neurons through anti-inflammatory actions via decreased microglial activation ${ }^{[98]}$, which appears to play a possible role in initiating or amplifying DAergic neuronal injury ${ }^{[99-101]}$; (4) nicotine administration can significantly ameliorate PD symptoms such as tremor, rigidity, bradykinesia, and gait disturbance including frozen gait ${ }^{[102-104]}$ and attenuate levodopa-induced dyskinesias ${ }^{[90,105]}$; and (5) nicotine may also act through non-receptor-mediated actions by decreasing ROS generation and oxidative stress and promoting mitochondrial function $^{[106-108]}$. Collectively, evidence suggests that nicotine mainly produces its beneficial effects on PD through nAChRs expressed in nigrostriatal DAergic system. In order to gain further insight into the nAChR subtypes involved in modulating DAergic function and characterization of changes in their expression with nigrostriatal damage, the development of PD therapies that slow or prevent the disorder by using $\mathrm{nAChR}$ ligands could be a useful strategy.

Experiments carried out on rodents, primates, and humans have shown that $\alpha 6^{*}$-nAChRs and $\alpha 4 \beta 2^{*}$-nAChRs are the major $n A C h R$ subtypes in the nigrostriatal system ${ }^{[16,37,109-114]}$, while $\alpha 7$-nAChRs are expressed to a lesser extent ${ }^{[110,111,115]}$.
Nicotine may act through $a 6^{*}$-nAChRs mainly expressed on DAergic terminals and stimulate DA release from striatal synaptosomes ${ }^{[38]}$. More importantly, $\alpha 6 \beta 2^{*}$-nAChRs, but not $\alpha 4 \beta 2^{*}$-nAChRs, are significantly decreased and this decrease closely accompanies nigrostriatal DAergic deficits caused by paraquat treatment ${ }^{[116]}$, suggesting that chronic nicotine administration may produce its neuroprotective effects on nigrostriatal DAergic neurons through the actication of a select population of $a 6^{*}$-nAChRs in mice ${ }^{[116]}$. The same phenomena is seen in both monkeys and humans based on Bordia and coworkers' finding that $\alpha 6 \alpha 4 \beta 2 \beta 3-\mathrm{nAChR}$ is preferentially vulnerable to nigrostriatal damage in monkey treated with MPTP and patients with $\mathrm{PD}^{[111]}$. These observations indicate that $\alpha 6^{*}$-nAChRs in the nigrostriatal DAergic system are promising targets for selective preventive treatment of PD. The development of selective $a 6^{*}$-nAChR ligands is attracting attention and will hold promise for PD therapies.

\section{Conclusion}

Neuronal nAChRs are richly expressed in the central nervous system, however, the $a 6^{*}$-nAChRs are found at the highest concentrations in both mesocorticolimbic and nigrostriatal pathways, and are particularly present in presynaptic nerve terminals. Functional $a 6^{*}$-nAChRs in mesocorticolimbic and nigrostriatal DAergic systems may play crucial roles in nicotine addiction and be of potential therapeutic value in PD. However, we are only beginning to understand the distribution of $\mathrm{nAChR} a 6$ subunit in neuronal networks and know very little about its physiological functions and pharmacological properties. At present, the daunting challenge is the development of $a 6^{*}$-nAChRs selective ligands for both basic research and future clinical treatment of human disorders in which $a 6^{*}$ $\mathrm{nAChRs} \mathrm{have} \mathrm{been} \mathrm{implicated,} \mathrm{such} \mathrm{as} \mathrm{nicotine} \mathrm{reinforcement}$ and PD.

\section{Acknowledgements}

This project was supported by grants from the Arizona Biomedical Research Commission (0028 and 0057), the Institute for Mental Health Research, and Philip Morris International through their External Research Program (RJL 2005-2008; Jie WU 2007-2010). Authors thank Dr Alain R SIMARD for his help to read and edit the manuscript.

\section{References}

1 Betz H. Ligand-gated ion channels in the brain: the amino acid receptor superfamily. Neuron 1990; 5: 383-92. 
2 Rezvani AH, Levin ED. Cognitive effects of nicotine. Biol Psychiatry 2001; 49: 258-67.

3 Millar NS, Harkness PC. Assembly and trafficking of nicotinic acetylcholine receptors. Mol Membr Biol 2008; 25: 279-92.

4 Millar NS, Gotti C. Diversity of vertebrate nicotinic acetylcholine receptors. Neuropharmacology 2009; 56: 237-46.

5 Hogg RC, Raggenbass M, Bertrand D. Nicotinic acetylcholine receptors: from structure to brain function. Rev Physiol Biochem Pharmacol 2003; 147: 1-46.

6 Bertrand D. Neuronal Nicotinic Acetylcholine Receptors and Epilepsy. Epilepsy Curr 2002; 2: 191-3.

7 Corringer PJ, Bertrand S, Galzi JL, Devillers-Thiery A, Changeux JP, Bertrand D. Molecular basis of the charge selectivity of nicotinic acetylcholine receptor and related ligand-gated ion channels. Novartis Found Symp 1999; 225: 215-24; discussion 24-30.

8 Corringer PJ, Le Novere N, Changeux JP. Nicotinic receptors at the amino acid level. Annu Rev Pharmacol Toxicol 2000; 40: 431-58.

9 Luetje CW, Patrick J. Both alpha- and beta-subunits contribute to the agonist sensitivity of neuronal nicotinic acetylcholine receptors. J Neurosci 1991; 11: 837-45.

$10 \mathrm{Wu}$ J, Liu Q, Yu K, Hu J, Kuo YP, Segerberg M, et al. Roles of nicotinic acetylcholine receptor beta subunits in function of human alpha4-containing nicotinic receptors. J Physiol 2006; 576 (Pt 1): 103-18.

11 Le Novere N, Changeux JP. Molecular evolution of the nicotinic acetylcholine receptor: an example of multigene family in excitable cells. J Mol Evol 1995; 40: 155-72.

12 Mann EO, Mody I. The multifaceted role of inhibition in epilepsy: seizure-genesis through excessive GABAergic inhibition in autosomal dominant nocturnal frontal lobe epilepsy. Curr Opin Neurol 2008; 21: 155-60.

13 Deneris ES, Connolly J, Rogers SW, Duvoisin R. Pharmacological and functional diversity of neuronal nicotinic acetylcholine receptors. Trends Pharmacol Sci 1991; 12: 34-40.

14 Sargent PB. The diversity of neuronal nicotinic acetylcholine receptors. Annu Rev Neurosci 1993; 16: 403-43.

15 Gerzanich V, Kuryatov A, Anand R, Lindstrom J. "Orphan" alpha6 nicotinic AChR subunit can form a functional heteromeric acetylcholine receptor. Mol Pharmacol 1997; 51:320-7.

16 Champtiaux N, Gotti C, Cordero-Erausquin M, David DJ, Przybylski C, Lena C, et al. Subunit composition of functional nicotinic receptors in dopaminergic neurons investigated with knock-out mice. J Neurosci 2003; 23: 7820-9.

17 le Novere N, Zoli M, Lena C, Ferrari R, Picciotto MR, MerloPich E, et al. Involvement of alpha6 nicotinic receptor subunit in nicotine-elicited locomotion, demonstrated by in vivo antisense oligonucleotide infusion. Neuroreport 1999; 10: 2497-501.

18 Larsson A, Jerlhag E, Svensson L, Soderpalm B, Engel JA. Is an alpha-conotoxin MII-sensitive mechanism involved in the neurochemical, stimulatory, and rewarding effects of ethanol? Alcohol 2004; 34: 239-50.

19 Quik M, Bordia T, O'Leary K. Nicotinic receptors as CNS targets for Parkinson's disease. Biochem Pharmacol 2007; 74: 1224-34.

20 Quik M, McIntosh JM. Striatal alpha6* nicotinic acetylcholine receptors: potential targets for Parkinson's disease therapy. J Pharmacol Exp Ther 2006; 316: 481-9.

21 Jerlhag E, Egecioglu E, Dickson SL, Svensson L, Engel JA. Alpha- conotoxin MII-sensitive nicotinic acetylcholine receptors are involved in mediating the ghrelin-induced locomotor stimulation and dopamine overflow in nucleus accumbens. Eur Neuropsychopharmacol 2008; 18: 508-18.

22 Yang $\mathrm{K}, \mathrm{Hu}$ J, Lucero L, Liu Q, Zheng C, Zhen X, et al. Distinctive nicotinic acetylcholine receptor functional phenotypes of rat ventral tegmental area dopaminergic neurons. J Physiol 2009; 587 (Pt 2): 345-61.

23 Le Novere N, Zoli M, Changeux JP. Neuronal nicotinic receptor alpha 6 subunit mRNA is selectively concentrated in catecholaminergic nuclei of the rat brain. Eur J Neurosci 1996; 8: 2428-39.

24 Azam L, Winzer-Serhan UH, Chen Y, Leslie FM. Expression of neuronal nicotinic acetylcholine receptor subunit mRNAs within midbrain dopamine neurons. J Comp Neurol 2002; 444: 260-74.

25 Klink R, de Kerchove d'Exaerde A, Zoli M, Changeux JP. Molecular and physiological diversity of nicotinic acetylcholine receptors in the midbrain dopaminergic nuclei. J Neurosci 2001; 21: 1452-63.

26 Fucile S, Matter JM, Erkman L, Ragozzino D, Barabino B, Grassi F, et al. The neuronal alpha6 subunit forms functional heteromeric acetylcholine receptors in human transfected cells. Eur J Neurosci 1998; 10: 172-8.

27 Champtiaux N, Han ZY, Bessis A, Rossi FM, Zoli M, Marubio $\mathrm{L}$, et al. Distribution and pharmacology of alpha 6-containing nicotinic acetylcholine receptors analyzed with mutant mice. J Neurosci 2002; 22: 1208-17.

28 Itier V, Bertrand D. Neuronal nicotinic receptors: from protein structure to function. FEBS Lett 2001; 504: 118-25.

29 Keiger CJ, Walker JC. Individual variation in the expression profiles of nicotinic receptors in the olfactory bulb and trigeminal ganglion and identification of alpha2, alpha6, alpha9, and beta3 transcripts. Biochem Pharmacol 2000; 59: 233-40.

30 Mameli-Engvall M, Evrard A, Pons S, Maskos U, Svensson TH, Changeux JP, et al. Hierarchical control of dopamine neuronfiring patterns by nicotinic receptors. Neuron 2006; 50: 911-21.

31 Zoli M, Lena C, Picciotto MR, Changeux JP. Identification of four classes of brain nicotinic receptors using beta2 mutant mice. J Neurosci 1998; 18: 4461-72.

32 Jiang L, Role LW. Facilitation of cortico-amygdala synapses by nicotine: activity-dependent modulation of glutamatergic transmission. J Neurophysiol 2008; 99: 1988-99.

33 Wonnacott S. Presynaptic nicotinic ACh receptors. Trends Neurosci 1997; 20: 92-8.

34 Lena C, Changeux JP, Mulle C. Evidence for "preterminal" nicotinic receptors on GABAergic axons in the rat interpeduncular nucleus. J Neurosci 1993; 13: 2680-8.

35 Keath JR, Iacoviello MP, Barrett LE, Mansvelder HD, McGehee DS. Differential modulation by nicotine of substantia nigra versus ventral tegmental area dopamine neurons. J Neurophysiol 2007; 98: 3388-96.

36 Zoli M, Moretti M, Zanardi A, McIntosh JM, Clementi F, Gotti C. Identification of the nicotinic receptor subtypes expressed on dopaminergic terminals in the rat striatum. J Neurosci 2002; 22: 8785-9.

37 Salminen O, Murphy KL, McIntosh JM, Drago J, Marks MJ, Collins AC, et al. Subunit composition and pharmacology of two classes of striatal presynaptic nicotinic acetylcholine receptors mediating dopamine release in mice. Mol Pharmacol 2004; 65: 
$1526-35$.

38 Azam L, McIntosh JM. Effect of novel alpha-conotoxins on nicotine-stimulated $\left[{ }^{3} \mathrm{H}\right]$ dopamine release from rat striatal synaptosomes. J Pharmacol Exp Ther 2005; 312: 231-7.

39 Drenan RM, Grady SR, Whiteaker P, McClure-Begley T, McKinney S, Miwa JM, et al. In vivo activation of midbrain dopamine neurons via sensitized, high-affinity alpha $6^{*}$ nicotinic acetylcholine receptors. Neuron 2008; 60: 123-36.

40 Barnard EA, Miledi R, Sumikawa K. Translation of exogenous messenger RNA coding for nicotinic acetylcholine receptors produces functional receptors in Xenopus oocytes. Proc R Soc Lond B Biol Sci 1982; 215: 241-6.

41 Miledi R, Parker I, Sumikawa K. Properties of acetylcholine receptors translated by cat muscle mRNA in Xenopus oocytes. Embo J 1982; 1: 1307-12.

42 Harvey SC, Luetje CW. Determinants of competitive antagonist sensitivity on neuronal nicotinic receptor beta subunits. J Neurosci 1996; 16: 3798-806.

43 Azam L, Yoshikami D, McIntosh JM. Amino acid residues that confer high selectivity of the alpha6 nicotinic acetylcholine receptor subunit to alpha-conotoxin MII[S4A,E11A,L15A]. J Biol Chem 2008; 283: 11625-32.

44 Kuryatov A, Olale F, Cooper J, Choi C, Lindstrom J. Human alpha6 AChR subtypes: subunit composition, assembly, and pharmacological responses. Neuropharmacology 2000; 39: 2570-90.

45 Dowell C, Olivera BM, Garrett JE, Staheli ST, Watkins M, Kuryatov A, et al. Alpha-conotoxin PIA is selective for alpha6 subunit-containing nicotinic acetylcholine receptors. J Neurosci 2003; 23: 8445-52.

46 Papke RL, Dwoskin LP, Crooks PA, Zheng G, Zhang Z, McIntosh $\mathrm{JM}$, et al. Extending the analysis of nicotinic receptor antagonists with the study of alpha6 nicotinic receptor subunit chimeras. Neuropharmacology 2008; 54: 1189-200.

47 McIntosh JM, Azam L, Staheli S, Dowell C, Lindstrom JM, Kuryatov A, et al. Analogs of alpha-conotoxin MII are selective for alpha6-containing nicotinic acetylcholine receptors. Mol Pharmacol 2004; 65: 944-52.

48 Vailati S, Hanke W, Bejan A, Barabino B, Longhi R, Balestra B, et al. Functional alpha6-containing nicotinic receptors are present in chick retina. Mol Pharmacol 1999; 56: 11-9.

49 Moretti M, Vailati S, Zoli M, Lippi G, Riganti L, Longhi R, et al. Nicotinic acetylcholine receptor subtypes expression during rat retina development and their regulation by visual experience. Mol Pharmacol 2004; 66: 85-96.

50 McIntosh JM, Santos AD, Olivera BM. Conus peptides targeted to specific nicotinic acetylcholine receptor subtypes. Annu Rev Biochem 1999; 68: 59-88.

51 Pereira EF, Alkondon M, McIntosh JM, Albuquerque EX. Alphaconotoxin-ImI: a competitive antagonist at alpha-bungarotoxinsensitive neuronal nicotinic receptors in hippocampal neurons. J Pharmacol Exp Ther 1996; 278: 1472-83.

52 Luo S, Kulak JM, Cartier GE, Jacobsen RB, Yoshikami D, Olivera $\mathrm{BM}$, et al. alpha-conotoxin AuIB selectively blocks alpha3 beta4 nicotinic acetylcholine receptors and nicotine-evoked norepinephrine release. J Neurosci 1998; 18: 8571-9.

53 Cartier GE, Yoshikami D, Gray WR, Luo S, Olivera BM, McIntosh JM. A new alpha-conotoxin which targets alpha3beta2 nicotinic acetylcholine receptors. J Biol Chem 1996; 271: 7522-8.

54 Harvey SC, McIntosh JM, Cartier GE, Maddox FN, Luetje CW. Determinants of specificity for alpha-conotoxin MII on alpha3beta2 neuronal nicotinic receptors. Mol Pharmacol 1997; 51:336-42.

55 Whiteaker P, Peterson CG, Xu W, McIntosh JM, Paylor R, Beaudet $\mathrm{AL}$, et al. Involvement of the alpha3 subunit in central nicotinic binding populations. J Neurosci 2002; 22: 2522-9.

56 Chi SW, Kim DH, Olivera BM, McIntosh JM, Han KH. NMR structure determination of alpha-conotoxin BuIA, a novel neuronal nicotinic acetylcholine receptor antagonist with an unusual 4/4 disulfide scaffold. Biochem Biophys Res Commun 2006; 349: 1228-34.

57 Azam L, Dowell C, Watkins M, Stitzel JA, Olivera BM, McIntosh JM. Alpha-conotoxin BuIA, a novel peptide from Conus bullatus, distinguishes among neuronal nicotinic acetylcholine receptors. J Biol Chem 2005; 280: 80-7.

58 Maskos U, Molles BE, Pons S, Besson M, Guiard BP, Guilloux JP, et al. Nicotine reinforcement and cognition restored by targeted expression of nicotinic receptors. Nature 2005; 436: 103-7.

59 Everitt BJ, Robbins TW. Neural systems of reinforcement for drug addiction: from actions to habits to compulsion. Nat Neurosci 2005; 8: 1481-9.

60 Wise RA. Dopamine, learning and motivation. Nat Rev Neurosci 2004; 5: 483-94.

61 Wonnacott S. Gates and filters: unveiling the physiological roles of nicotinic acetylcholine receptors in dopaminergic transmission. Br J Pharmacol 2008; 153 Suppl 1: S2-4.

62 Dajas-Bailador F, Wonnacott S. Nicotinic acetylcholine receptors and the regulation of neuronal signalling. Trends Pharmacol Sci 2004; 25: 317-24.

63 McGehee DS, Heath MJ, Gelber S, Devay P, Role LW. Nicotine enhancement of fast excitatory synaptic transmission in CNS by presynaptic receptors. Science 1995; 269: 1692-6.

64 Sher E, Chen Y, Sharples TJ, Broad LM, Benedetti G, Zwart R, et al. Physiological roles of neuronal nicotinic receptor subtypes: new insights on the nicotinic modulation of neurotransmitter release, synaptic transmission and plasticity. Curr Top Med Chem 2004; 4: 283-97.

65 Dani JA, Bertrand D. Nicotinic acetylcholine receptors and nicotinic cholinergic mechanisms of the central nervous system. Annu Rev Pharmacol Toxicol 2007; 47: 699-729.

66 Vernino S, Amador M, Luetje CW, Patrick J, Dani JA. Calcium modulation and high calcium permeability of neuronal nicotinic acetylcholine receptors. Neuron 1992; 8: 127-34.

67 Seguela P, Wadiche J, Dineley-Miller K, Dani JA, Patrick JW. Molecular cloning, functional properties, and distribution of rat brain alpha 7: a nicotinic cation channel highly permeable to calcium. J Neurosci 1993; 13: 596-604.

68 Castro NG, Albuquerque EX. alpha-Bungarotoxin-sensitive hippocampal nicotinic receptor channel has a high calcium permeability. Biophys J 1995; 68: 516-24.

69 Sharma G, Vijayaraghavan S. Modulation of presynaptic store calcium induces release of glutamate and postsynaptic firing. Neuron 2003; 38: 929-39.

70 Tredway TL, Guo JZ, Chiappinelli VA. N-type voltage-dependent calcium channels mediate the nicotinic enhancement of GABA release in chick brain. J Neurophysiol 1999; 81: 447-54. 
71 Dani JA, De Biasi M. Cellular mechanisms of nicotine addiction. Pharmacol Biochem Behav 2001; 70: 439-46.

72 Dani JA, Ji D, Zhou FM. Synaptic plasticity and nicotine addiction. Neuron 2001; 31:349-52.

73 Mansvelder HD, McGehee DS. Long-term potentiation of excitatory inputs to brain reward areas by nicotine. Neuron 2000; 27 : 349-57.

74 Mansvelder HD, Keath JR, McGehee DS. Synaptic mechanisms underlie nicotine-induced excitability of brain reward areas. Neuron 2002; 33: 905-19.

75 Oakman SA, Faris PL, Kerr PE, Cozzari C, Hartman BK. Distribution of pontomesencephalic cholinergic neurons projecting to substantia nigra differs significantly from those projecting to ventral tegmental area. J Neurosci 1995; 15: 5859-69.

76 Bolam JP, Francis CM, Henderson Z. Cholinergic input to dopaminergic neurons in the substantia nigra: a double immunocytochemical study. Neuroscience 1991; 41: 483-94.

77 Hogg RC, Bertrand D. Regulating the regulators: the role of nicotinic acetylcholine receptors in human epilepsy. Drug News Perspect 2003; 16: 261-6.

78 Di Chiara G, Imperato A. Drugs abused by humans preferentially increase synaptic dopamine concentrations in the mesolimbic system of freely moving rats. Proc Natl Acad Sci USA 1988; 85: 5274-8.

79 Schilstrom B, Nomikos GG, Nisell M, Hertel P, Svensson TH. $N$-methyl- $D$-aspartate receptor antagonism in the ventral tegmental area diminishes the systemic nicotine-induced dopamine release in the nucleus accumbens. Neuroscience 1998; 82: 781-9.

80 Yang K, Lukas R, Wu J. Functional alpha-6 nicotinic acetylcholine receptors located pre-synaptic, GABAergic boutons in rat midbrain dopaminergic neurons participate in cholinergic of GABA release. Neurosci Abstr 37 2007; 573.14.

81 Exley R, Clements MA, Hartung H, McIntosh JM, Cragg SJ. Alpha6-containing nicotinic acetylcholine receptors dominate the nicotine control of dopamine neurotransmission in nucleus accumbens. Neuropsychopharmacology 2008; 33: 2158-66.

82 Shytle RD, Silver AA, Lukas RJ, Newman MB, Sheehan DV, Sanberg PR. Nicotinic acetylcholine receptors as targets for antidepressants. Mol Psychiatry 2002; 7: 525-35.

83 Pons S, Fattore L, Cossu G, Tolu S, Porcu E, McIntosh JM, et al. Crucial role of alpha4 and alpha6 nicotinic acetylcholine receptor subunits from ventral tegmental area in systemic nicotine selfadministration. J Neurosci 2008; 28: 12318-27.

84 Meyer EL, Yoshikami D, McIntosh JM. The neuronal nicotinic acetylcholine receptors alpha $4^{*}$ and alpha6* differentially modulate dopamine release in mouse striatal slices. J Neurochem 2008; 105: 1761-9.

85 Exley R, Cragg SJ. Presynaptic nicotinic receptors: a dynamic and diverse cholinergic filter of striatal dopamine neurotransmission. Br J Pharmacol 2008; 153 Suppl 1: S283-97.

86 Cragg SJ. Meaningful silences: how dopamine listens to the ACh pause. Trends Neurosci 2006; 29: 125-31.

87 Yang K, Jin G, Wu J. The neuropharmacology of (-)-stepholidine and its potential applications. Curr Neuropharmacol 2007; 5: 289-94.

88 Sulzer D. Multiple hit hypotheses for dopamine neuron loss in Parkinson's disease. Trends Neurosci 2007; 30: 244-50.
89 Thacker EL, O’Reilly EJ, Weisskopf MG, Chen H, Schwarzschild MA, McCullough ML, et al. Temporal relationship between cigarette smoking and risk of Parkinson disease. Neurology 2007; 68: 764-8.

90 Quik M, O’Leary K, Tanner CM. Nicotine and Parkinson's disease: implications for therapy. Mov Disord 2008; 23: 1641-52.

91 Quik M. Smoking, nicotine and Parkinson's disease. Trends Neurosci 2004; 27: 561-8.

92 Morens DM, Grandinetti A, Reed D, White LR, Ross GW. Cigarette smoking and protection from Parkinson's disease: false association or etiologic clue? Neurology 1995; 45: 1041-51.

93 Allam MF, Campbell MJ, Hofman A, Del Castillo AS, FernandezCrehuet Navajas R. Smoking and Parkinson's disease: systematic review of prospective studies. Mov Disord 2004; 19: 614-21.

94 Zhou FM, Liang Y, Dani JA. Endogenous nicotinic cholinergic activity regulates dopamine release in the striatum. Nat Neurosci 2001; 4: 1224-9.

95 Grady S, Marks MJ, Wonnacott S, Collins AC. Characterization of nicotinic receptor-mediated $\left[{ }^{3} \mathrm{H}\right]$ dopamine release from synaptosomes prepared from mouse striatum. J Neurochem 1992; 59: 848-56.

96 Picciotto MR, Zoli M. Neuroprotection via nAChRs: the role of nAChRs in neurodegenerative disorders such as Alzheimer's and Parkinson's disease. Front Biosci 2008; 13: 492-504.

97 Ward RJ, Lallemand F, de Witte P, Dexter DT. Neurochemical pathways involved in the protective effects of nicotine and ethanol in preventing the development of Parkinson's disease: potential targets for the development of new therapeutic agents. Prog Neurobiol 2008; 85: 135-47.

98 Park HJ, Lee PH, Ahn YW, Choi YJ, Lee G, Lee DY, et al. Neuroprotective effect of nicotine on dopaminergic neurons by antiinflammatory action. Eur J Neurosci 2007; 26: 79-89.

99 Cho BP, Song DY, Sugama S, Shin DH, Shimizu Y, Kim SS, et al. Pathological dynamics of activated microglia following medial forebrain bundle transection. Glia 2006; 53: 92-102.

100 Gao HM, Hong JS, Zhang W, Liu B. Distinct role for microglia in rotenone-induced degeneration of dopaminergic neurons. J Neurosci 2002; 22: 782-90.

101 Le W, Rowe D, Xie W, Ortiz I, He Y, Appel SH. Microglial activation and dopaminergic cell injury: an in vitro model relevant to Parkinson's disease. J Neurosci 2001; 21: 8447-55.

102 Meshul CK, Kamel D, Moore C, Kay TS, Krentz L. Nicotine alters striatal glutamate function and decreases the apomorphineinduced contralateral rotations in 6-OHDA-lesioned rats. Exp Neurol 2002; 175: 257-74.

103 Domino EF, Ni L, Zhang H. Nicotine alone and in combination with L-DOPA methyl ester or the $\mathrm{D}_{2}$ agonist N-0923 in MPTPinduced chronic hemiparkinsonian monkeys. Exp Neurol 1999; 158: 414-21.

104 Ishikawa A, Miyatake T. Effects of smoking in patients with earlyonset Parkinson's disease. J Neurol Sci 1993; 117: 28-32.

105 Quik M, Cox H, Parameswaran N, O’Leary K, Langston JW, Di Monte D. Nicotine reduces levodopa-induced dyskinesias in lesioned monkeys. Ann Neurol 2007; 62: 588-96.

106 Ferger B, Spratt C, Earl CD, Teismann P, Oertel WH, Kuschinsky $\mathrm{K}$. Effects of nicotine on hydroxyl free radical formation in vitro and on MPTP-induced neurotoxicity in vivo. Naunyn Schmiedebergs Arch Pharmacol 1998; 358: 351-9. 
107 Cormier A, Morin C, Zini R, Tillement JP, Lagrue G. Nicotine protects rat brain mitochondria against experimental injuries. Neuropharmacology 2003; 44: 642-52.

108 Cormier A, Morin C, Zini R, Tillement JP, Lagrue G. In vitro effects of nicotine on mitochondrial respiration and superoxide anion generation. Brain Res 2001; 900: 72-9.

109 Quik M, Polonskaya Y, Kulak JM, McIntosh JM. Vulnerability of ${ }^{125}$ I-alpha-conotoxin MII binding sites to nigrostriatal damage in monkey. J Neurosci 2001; 21: 5494-500.

110 Quik M, Vailati S, Bordia T, Kulak JM, Fan H, McIntosh JM, et al. Subunit composition of nicotinic receptors in monkey striatum: effect of treatments with 1-methyl-4-phenyl-1,2,3,6tetrahydropyridine or L-DOPA. Mol Pharmacol 2005; 67: 32-41.

111 Bordia T, Grady SR, McIntosh JM, Quik M. Nigrostriatal damage preferentially decreases a subpopulation of alpha6beta2* nAChRs in mouse, monkey, and Parkinson's disease striatum. Mol Pharmacol 2007; 72: 52-61.

112 Court J, Clementi F. Distribution of nicotinic subtypes in human brain. Alzheimer Dis Assoc Disord 1995; 9 Suppl 2: 6-14.

113 Bohr IJ, Ray MA, McIntosh JM, Chalon S, Guilloteau D, McKeith IG, et al. Cholinergic nicotinic receptor involvement in movement disorders associated with Lewy body diseases. An autoradiography study using $\left[{ }^{125} \mathrm{I}\right]$ alpha-conotoxinMII in the striatum and thalamus. Exp Neurol 2005; 191: 292-300.

114 Quik M, Bordia T, Forno L, McIntosh JM. Loss of alphaconotoxinMII- and A85380-sensitive nicotinic receptors in Parkinson's disease striatum. J Neurochem 2004; 88: 668-79.

115 Clarke PB, Schwartz RD, Paul SM, Pert CB, Pert A. Nicotinic binding in rat brain: autoradiographic comparison of $\left[{ }^{3} \mathrm{H}\right]$ acetylcholine, $\left[{ }^{3} \mathrm{H}\right]$ nicotine, and $\left[{ }^{125} \mathrm{I}\right]$-alpha-bungarotoxin. J Neurosci 1985; 5: 1307-15.

116 Khwaja M, McCormack A, McIntosh JM, Di Monte DA, Quik M. Nicotine partially protects against paraquat-induced nigrostriatal damage in mice; link to alpha6beta2 ${ }^{*}$ nAChRs. J Neurochem 2007; 100: 180-90. 